\title{
Clay-salt slimes of the "Belaruskali" - novel sorbents for management of liquid radioactive wastes and decontamination of environmental water streams
}

\author{
L. Fuks ${ }^{1} \cdot$ L. Maskalchuk ${ }^{2} \cdot$ I. Herdzik-Koniecko ${ }^{1} \cdot$ T. Leontieva $^{3}$
}

Received: 24 October 2018 / Published online: 19 February 2019

(c) The Author(s) 2019

\begin{abstract}
Clay-salt slimes, production wastes from "Belaruskali" (A Belarusian factory, producing potash fertilizers), have been tested as a low-cost, eco-friendly potential sorbent for the removal of radionuclides from aqueous solutions, and may be a component of the cement filling of drums used in the storage of radioactive wastes. The efficiency of sorptive removal of caesium(I)-137, strontium(II)-90, europium(III)-152, and americium(III)-241 was examined with respect to the time of phase equilibration, $\mathrm{pH}$, sorbent dosage, and the presence of salts and complexing agents. Irradiation stability of the material was also studied. It was found that uptake of the radionuclides is almost complete. A procedure for the removal of technetium- 99 has been also proposed. Experimental results obtained within the presented work confirm our expectations.
\end{abstract}

Keywords Clay-salt slimes $\cdot$ Radionuclides $\cdot$ Sorbents $\cdot$ Radioactively contaminated water $\cdot$ Waste management $\cdot$ Radioecology

\section{Introduction}

In Poland, low- and medium-level short-lived radioactive wastes (LLRW and MLRW, respectively) ${ }^{1}$ are conditioned in the near-surface National Radioactive Waste Repository (NRWR in Rozan) operated by the Radioactive Waste Management Plant [1]. In 2016 NRWR collected about fifty cubic meters of wastes, with about $40 \%$ being liquid. Also collected, were about 24,000 smoke detectors and 1300 decommissioned sealed radioactive sources [1]. Radiochemical analyses of samples withdrawn from these liquid

L. Fuks

leon.ichtj@gmail.com

$\square$ I. Herdzik-Koniecko

i.herdzik@ichtj.waw.pl

1 Centre for Radiochemistry and Nuclear Chemistry, Institute of Nuclear Chemistry and Technology, 16, Dorodna Str., 03-195 Warsaw, Poland

2 Belarusian State University of Technology, 13a, Sverdlova Str., 220006 Minsk, Belarus

3 State Scientific Institution "Joint Institute for Power and Nuclear Research - Sosny", National Academy of Sciences of Belarus, P.O. Box 119, 220109 Minsk, Belarus radioactive wastes have shown, with the exception of $\mathrm{H}-3$ (about 22\%), the most important contribution to the total radiation activity comes from Co-60 (44\%) and Cs-137 (11.4\%). The main radionuclides present in Polish liquid wastes are shown in Fig. 1.

In Belarus, the country of the second group of authors of the presented work, LLRW and MLRW will be stored in an area near the nuclear power plant (at present, under construction) before being removed to the repository. This will be constructed by 2028. [3].

Liquid radioactive wastes pose a unique problem because of their relatively large volume. According to current legal regulations, it is not permitted to dilute radioactively contaminated liquids to reduce their radioactivity level below the value which permits their release into the environment. Therefore, different physical and/or chemical methods for concentration/solidification of the dangerous matter (which may be subsequently stored) have been already developed. Sorption is amongst the most popular methods because is low-cost, effective, and easy to carry out.

Another problem related to LLRW and MLRW management is the possibility of leaching of radioactive elements

\footnotetext{
${ }^{1}$ French radioactive waste classification system, based on the criteria of radioactivity level and life span determined by the half-life, $\mathrm{T}$, of the main radioelements in the waste. [5].
} 


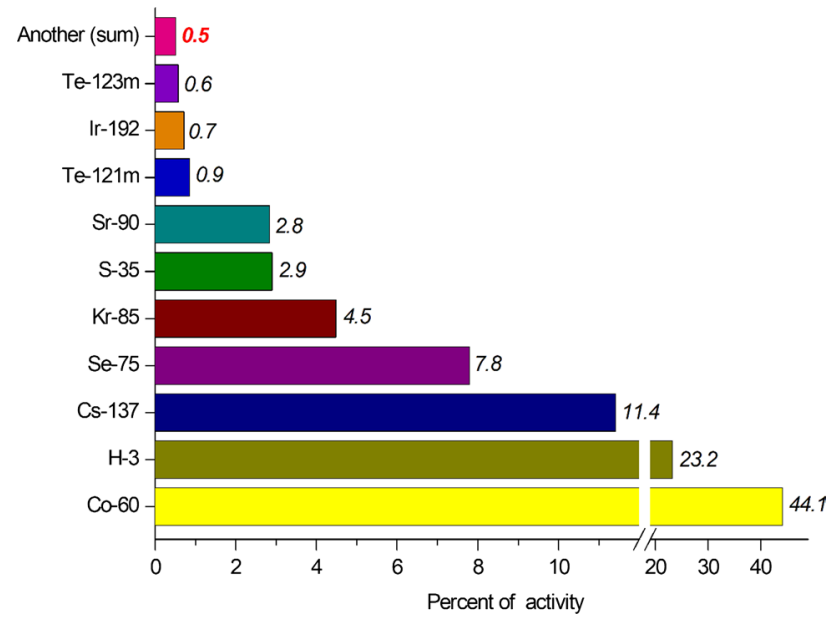

Fig. 1 Ten major radionuclides present in the Polish LLRW at 31.12.2016 [2]

by different aqueous streams present in the repository, [4] which may result in dangerous health effects in both humans and animals within the local environment. So, the secure management of liquid radioactive wastes is an important, increasing problem world-wide. To prevent the abovementioned release of hazardous radioactive elements from storage locations into the environment, a well-known multi-barrier system was put into effect. Typically, the main retardation barrier for the release of radionuclides is the immobilization of radioactive wastes in different mixtures of cement and sorbents. For example, it has already been shown that the use of silica fume, ilmenite, or zeolites significantly decrease leaching rates [6-10]. It is well known that the usage of these barriers requires a large amount of natural materials exhibiting specific physicochemical and sorption properties. This can be prohibitive for the economic operation of large scale operations. For this application, the most promising option is using natural sorption materials, or industrial wastes of low price and effective sorption properties [11]. On the contrary, synthetic sorbents are expensive, and some of them have low selectivity. Therefore, to solve the problem of water contamination from leached radionuclides, attention is given to the search for novel sorbents, or to modify certain natural minerals with the aim to improve their sorption properties. At the same time, when dealing with already radioactively polluted water, decontamination of this medium becomes an urgent problem. In this case, sorption seems to be one of the most promising methods.

The identification of all the abovementioned problems resulted in a great number of studies aimed at assessing the sorption of different metallic radionuclides by a diverse range of cost-effective sorbents, including, amongst others, clays and zeolites [12-16]. The presently realized PolishBelarusian joint project presented in this paper is aimed at determining sorption characteristics of clay-salt slimes (CSS), a waste product created during the fabrication of potash fertilizers in Belaruskali (Soligorsk, Belarus). More precisely, the purpose of this work was to check their potential for usage in decontamination of radioactively contaminated aqueous solutions and as components of the engineering barriers in the radioactive waste repositories. Material from Mining Factory No 3 of the "Belaruskali" facility was the object of the presented studies. In previous papers, samples have been collected from factories No. 1 and 2 [17-19].

\section{Experimental}

\section{Materials}

Experiments were performed with clay-salt slimes (CSS3) samples withdrawn from the clay-salt slime repository mining factory No. 3 of the "Belaruskali" facility. The mineralogical composition of this material was determined by $\mathrm{X}$-ray diffraction analysis as illite, $51.1 \%$; dolomite, $19.6 \%$; potassium feldspar, 14.0\%; quartz, $7.4 \%$, and other minor minerals, $7.1 \%$. It was previously shown that the qualitative mineralogical composition is similar to that of samples obtained from the "Belaruskali" mining factory No 1, further referred to in this paper as CSS-1 [17-19].

The raw material from which the CSS-3 samples were obtained was taken from the repository in factory No. 3 . It was in the form of a clay suspension in a saturated salt solution. Therefore, as well as the water-insoluble components, after drying it also consisted of the water-soluble salts (mainly, $\mathrm{KCl}$ and $\mathrm{NaCl}$ ). This material was thoroughly washed with water to remove all the soluble salts and desiccated to constant mass $\left(55^{\circ} \mathrm{C} ; 6 \mathrm{~h}\right.$.). The resulting sample was designated CSS-3A. A portion of the CSS-3A sample was treated with $0.1 \mathrm{M} \mathrm{HCl}$ aqueous solution in order to destroy carbonates (until the emission of $\mathrm{CO}_{2}$ stopped; $50{ }^{\circ} \mathrm{C}$; stirring). The volume of $\mathrm{HCl}$ solution used for the destruction of most of the aluminosilicates was calculated based on their content in the CSS-3A sample. Then, the potential sorbent was rinsed several times with consecutive portions of distilled water. The solid-to-liquid ratio was 1:5 in each cycle. Finally, the sample was dried at $105^{\circ} \mathrm{C}$ until its constant mass was reached. The resulting material was designated CSS-3B.

It has been found that the main components of both CSS-3 materials are illite (42.2-51.1 wt \%) and dolomite (19.6-24.8 wt \%) [20]. Moreover, the average formula of illite was determined to be $\left(\mathrm{K}_{0.73} \mathrm{Na}_{0.27} \mathrm{Ca}_{0.15}\right)\left(\mathrm{Al}_{0.76} \mathrm{Mg}_{0.82} \mathrm{Fe}_{0.44}^{3+}\right)$ $\left[\mathrm{Si}_{3.47} \mathrm{Al}_{0.53}\right] \mathrm{O}_{10}(\mathrm{OH})_{2}$ [20]. In this formula, the first bracket relates to the ion-exchangeable layer, the second to the cations in the octahedral layer, and the components within the square bracket comprise the tetrahedral layer. It seems 
reasonable to state, that present in the interlayer of this clay, magnesium(II), calcium(II) and potassium(I) ions are crucial metals to be exchanged when sorption occurs. In turn, silicon(IV), aluminum(III), and iron(III) cations are the framework forming ions.

The specific surface area of the CSS-3A material was determined by low-temperature nitrogen adsorption and utilising Brunauer-Emmett-Teller theory (BET) to be about $66 \mathrm{~m}^{2} / \mathrm{g}$, and is twice greater than that of the raw material $\left(28 \mathrm{~m}^{2} / \mathrm{g}\right)$ [20].

\section{All other reagents were bought from Sigma-Aldrich Inc. (Poland branch). Deionized water was used in all the experiments}

Certified radioactive standard solutions of caesium-137 $\left(t_{1 / 2}=30.07\right.$ year; $\left.E_{\gamma}=661.7 \mathrm{keV}\right)$, strontium-85 $\left(t_{1 / 2}=64.8\right.$ day; $\left.E_{\gamma}=514 \mathrm{keV}\right)$, europium-152 $\left(t_{1 / 2}=13.5\right.$ year; $\left.E_{\gamma}=344.3 \mathrm{keV}\right)$ and americium-241 $\left(t_{1 / 2}=432.2\right.$ year; $\left.E_{\gamma}=59.5 \mathrm{keV}\right)$ were delivered by POLATOM (Otwock-Swierk, Poland). $\mathrm{NaTcO}_{4}-99 \mathrm{~m}$ solution (of radioactivity concentration of about $100 \mathrm{MBq} \mathrm{cm}^{-3}$ ) was obtained from a Mo-99/Tc-99m medical generator (GE Healthcare, provided by Biker, Warsaw, Poland). With the aim of obtaining solutions of the required concentrations of the radionuclides $\left(10-1000 \mathrm{kBq} \mathrm{cm}^{-3}\right)$, initial standards were diluted gravimetrically with nitric acid $\left(10^{-2}\right.$ M) and checked for their radioactive purity using gamma spectrometry.

\section{Instrumentation}

Sorption experiments were performed in $5 \mathrm{~mL}$ polyethylene vials shaken with the Heidolph Multi Reax test-tube shaker (Witco, Lodz, Poland). Phases were separated using the MPW-251 centrifuge (MPW Medicals Instruments, Poland) for $10 \mathrm{~min}$ at $14,000 \mathrm{rpm}$. Then, the gravimetrically withdrawn samples of aqueous phase were measured radiometrically with a Perkin Elmer 2480 Wizard2@ Automatic Gamma Counter (Polish branch, Warszawa). All radionuclides were measured simultaneously.

The electric potential in the interfacial double layer of the CSS materials (known as zeta potential, ZP) was estimated by calculating their electrophoretic mobility, which is proportional to their ZP. For this purpose, Zetasizer Nano ZS instrument, (Malvern, UK) with the dynamic light scattering was applied.

A closed source of Co-60 (Gamma Chamber GC 5000, Board of Radiation and Isotope Technology, India) with an activity of $550 \mathrm{MBq}$ was used for the irradiation of solid samples when studying radiation stability.

The FT-IR spectra of dried CSS specimens were recorded in the $4000-400 \mathrm{~cm}^{-1}$ region, prepared for analysis as $\mathrm{KBr}$ pellets, using the Nicolet iS10 (Spectro-Lab, Warszawa, Poland). Obtained numerical data in ASCII form were analyzed with OPUS software (Brucker, Germany).

\section{Sorption studies}

The study of sorption of the radioactive metals was performed in static conditions. Initial aqueous solutions (ca. $10^{-2} \mathrm{M} \mathrm{NaNO}_{3}$ ) were spiked with the radionuclides and placed in polyethylene test tubes, and then a weighed quantity of the sorbent was added. Samples were mechanically shaken for $2 \mathrm{~h}$. (except when studying sorption dependency on contact time) and separated by centrifuging. Radioactivity concentration of the radionuclides in the samples taken from the supernatant was measured and compared with that of the corresponding initial solution. Detailed values of the experimental parameters (volume of the solution, the mass of the sorbent added, $\mathrm{pH}$ ) are presented in Part 3.

All sorption studies were performed as three independent experiments and the radionuclide content was determined from a set of three samples measured in triplicate.

The amount of the radionuclide absorbed per $1 \mathrm{~g}$ of sorbent $\left(q_{\text {eq }}, \mathrm{Bq} \mathrm{g}^{-1}\right)$ was calculated using Eq. (1) given below:

$q_{\mathrm{eq}}=\left(A_{0}-A_{\mathrm{eq}}\right) \cdot \frac{V}{m}$

where $A_{0}$ is the initial concentration of the radionuclide in solution $\left(\mathrm{Bq} \mathrm{L}^{-1}\right), A_{\mathrm{eq}}$ the concentration of the radionuclide in the solution under equilibrium conditions, $m$ the mass of the sorbent $(\mathrm{g})$ and $V$ the volume of the solution used for sorption $(L)$. To be able to consider the effectiveness of a given sorbent, the efficiency of the solution purification, $\left(E_{\mathrm{r}}, \%\right)$, was calculated with the formula:

$E_{r}=\frac{\left(A_{0}-A_{\mathrm{eq}}\right)}{A_{0}} \cdot 100 \%$

If necessary, apparent distribution coefficients of the radionuclides between both phases $\left(K_{\mathrm{d}}, \mathrm{L} \mathrm{g}^{-1}\right)$ may be also calculated by means of Eq. 3 [21]:

$K_{\mathrm{d}}=\frac{\left(A_{0}-A_{\mathrm{eq}}\right)}{A_{\mathrm{eq}}} \cdot \frac{V}{m}$

\section{Additional properties of the CSS-3 materials}

\section{Homogeneity of the samples}

Before studies on radionuclide sorption were started, the homogeneity of the sorbent powder was confirmed using a method familiar to the laboratory of this work. It has been previously used for conducting interlaboratory comparisons 
Table 1 Controllable factors and their values

\begin{tabular}{|c|c|c|c|c|}
\hline No & Description & Studied values & Optimum value & Units \\
\hline 1 & Initial metal concentration & nca* & & $\mathrm{mol} \mathrm{dm}^{-3}$ \\
\hline 2 & Initial salt concentration & ca. $10^{-2} \mathrm{NaNO}_{3}$ & & M \\
\hline 3 & Temperature & Room temperature & & ${ }^{\circ} \mathrm{C}$ \\
\hline 4 & Time of contacting phases & $0,0.5,1,2,3,5,10,15,30,60,120$ and 180 & 60 & $\min$ \\
\hline 5 & Mass of sorbent used & From 1 to 20 & 5 & $\mathrm{~g} \mathrm{dm}^{-3}$ \\
\hline 6 & $\mathrm{pH}$ & $2-10$ & 5.5 & \\
\hline 7 & Presence of salts (no/yes) & $\mathrm{Na}^{+}, \mathrm{K}^{+}, \mathrm{Mg}^{2+}, \mathrm{Ca}^{2+}$ chlorides: $583,32,129$ and 182 & & $\mathrm{mg} \mathrm{dm}{ }^{-3}$ \\
\hline 8 & Presence of chelating agents (no/yes) & oxalic and citric acids and Na-EDTA: $2 \times 10^{-3}$, each & & M \\
\hline 9 & Irradiation dose & 250 & no & kGy \\
\hline
\end{tabular}

*No-carrier added (nca) radioisotope: extremely small amount of the radioactive isotope (usually in the range of $10^{-6}-10^{-7}$ mol) which is not stabilized with weight amount of its stable isotopes [22]

on the determination of activity concentration of radionuclides present in food and environmental samples (unpublished data). Homogeneity was confirmed by equilibration of seven randomly withdrawn samples (50 mg, each) of the CSS raw materials, CSS-3A and CSS-3B, with $5 \mathrm{~mL}$ of $0.1 \mathrm{M} \mathrm{NaNO}_{3}$ solution containing caesium-137. It was found, that the $E_{r}$ values did not differ significantly from each other. Mean $E_{r}$ values were established to be $98.81 \%$ with a standard deviation of mean being $0.43 \%$ and $98.64 \pm 0.47 \%$ for the CSS-3A and CSS-3B samples, respectively. Such small values of standard deviation suggest that both CSS materials are homogeneous.

\section{Desorption of radionuclides from the metal loaded sorbents by aqueous solutions}

Prior to starting the experiments, both studied materials were pre-equilibrated with an aqueous solution containing the radionuclides and dried. Desorption of radionuclides from these metal loaded sorbents by bi-distilled water was studied in a number of consecutive experiments. Each experiment involved equilibration of the loaded sorbent with water $\left(0.50 \mathrm{~g}\right.$ of the sorbent with $10 \mathrm{~mL}$ of water; Falcon ${ }^{\mathrm{TM}} 50 \mathrm{~mL}$ conical test tubes; RT) for several hours, separation of the phases (10 min.; centrifuging; 14,000 rpm) and radiometric determination of the radioactivity concentrations of the liquid phases. Equilibration time was increased gradually from $2 \mathrm{~h}$ until $120 \mathrm{~h}$ with steps of $12 \mathrm{~h}$.

\section{Radiation stability of the CSS materials}

Ten grams of both CSS-3A and CSS-3B were irradiated at room temperature with gamma radiation in a Gamma Chamber (GC 5000, Co-60 source). An irradiation dose of $250 \mathrm{kGy}$ was delivered within $50 \mathrm{~h}$. This dose exceeds by 25 times the FAO and WHO recommendation for the greatest dose to be used for food irradiation. Radiation stability of the samples was evaluated by employing three independent methods. In the first, the sorption properties of the irradiated samples were compared with those of the untreated samples. Secondly, infra-red spectra were recorded for the irradiated samples and compared with those of raw, non irradiated materials. Finally, the value of the ZP's were determined and compared to the non irradiated samples for both pairs of the potential sorbents.

Sorption experiments were performed by changing only one parameter in any series of experiments. Such methodology allows for identifying the optimum experimental conditions for sorption. List of the parameters, ranges of the studied values and the optimum sorption conditions are listed in Table 1.

\section{Results and discussion}

In the presented work, removal efficiency $\left(E_{\text {eq }}, \%\right)$ of $\mathrm{Cs}(\mathrm{I})$, $\mathrm{Sr}(\mathrm{II}), \mathrm{Eu}(\mathrm{III})$, and $\mathrm{Am}$ (III) metal ions by sorption with claysalt slimes (CSS) was studied, and it's dependence on certain factors significant in the safe management of liquid radioactive wastes was evaluated.

It is well known, that the Gibbs free energy equation, as given below, relates the free energy of reaction $\left(\Delta G^{\circ}\right.$, $\left.\mathrm{kJ} \mathrm{mol}^{-1}\right)$ to the equilibrium constant $\left(K_{\text {eq }}\right.$, dimensionless constant), and may be discussed in terms of the interaction between a metal cation and the counterion.

$\Delta G^{0}=R \cdot T \cdot \ln K_{e q}$

If so, it approximates energy of ion solvation in terms of its charge and radius, assuming predominantly electrostatic interactions. So, when plotting experimentally obtained $K_{\mathrm{d}}$ values for the studied metals with respect to the reciprocal of the Shannon ionic radii [23] (see, Fig. 2), a poor linear relationship is observed (e.g. for CSS-3A, $R^{2} \approx 0.89$ ). 


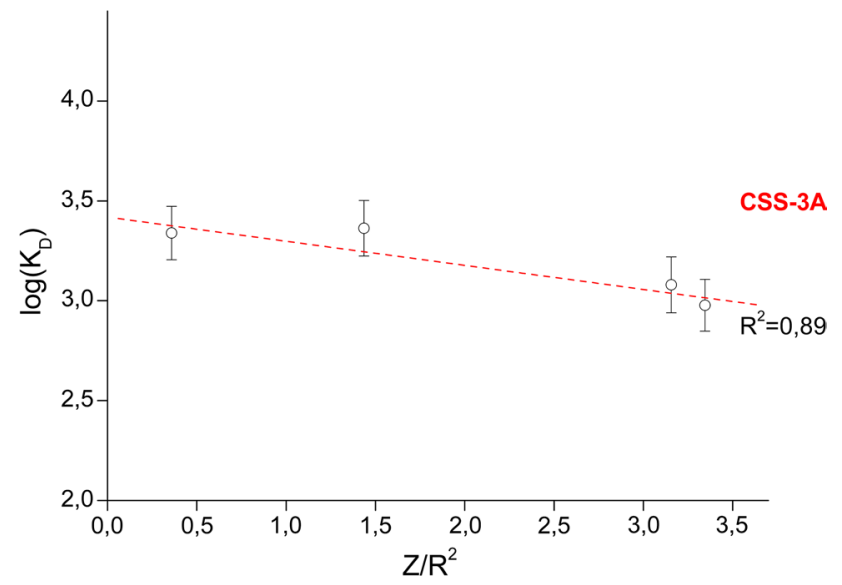

Fig. 2 The dependence of the logarithm of the sorption distribution coefficients in CSS-3A and water $(\mathrm{pH}=3.5)$, for the four radionuclides studied, on their inverse Shannon ionic radii [23]

This means that even if sorption of metals is governed by cation-anion electrostatic interactions, some further phenomena should be taken into account. One may imagine that primarily, the size of the cavities should be taken into consideration.

In the following text, we will present our experimental results on radionuclide sorption, described by the efficiency of the solution purification, $E_{\mathrm{r}}, \%$. Referring to the parameters of the experiments shown in Table 1, these values seem to be more informative in designing novel procedures for sorption.

\section{Sorption of radionuclides by the CSS-3 materials}

\section{Dependence of removal efficiency on the equilibration time}

The contact time of the phases is a crucial factor in determining the efficiency of the adsorption process $\left(E_{\text {eq }}\right)$.

As a rule, sorption of metal ions proceeds in several stages. In the first, the transfer of metal ions from the solution onto the sorbent takes place through a diffusion process. Then, these metal ions diffuse throughout the outer surface of the sorbent (film diffusion) or migrate inside through pores (pore diffusion) and interact with active sites of the sorbent. The overall rate of sorption is dominated by the slowest of these steps or, if the rates of several steps are comparable, is formed by a combination of them. So, for analysis of the sorption kinetics, the dependency of the $q_{\mathrm{eq}}$ values for different equilibration times on the initial and equilibrium metal concentrations should be analyzed. Such data allows for choosing the best model for fitting the reaction rate dependency on time of equilibration. The most popular equations are the pseudo-first order equation, pseudo-second order equation, the intramolecular diffusion based process, and the Elovich model. All these models are presented in detail in numerous papers, e.g. in that of Staron et al. [24].

In the presented work, we preferred the linear forms of equations describing the above models found in the paper of Staron [24]. Instead of metal masses, however, we preferred the activities of radiation emitted. If the specific activity of the radiation emitted by the particular radionuclide and the efficiency of the radiation counting (for modern counters this is constant within a broad range of radiation measured) are known, the activity of the radiation emitted by the solution studied is proportional to the radionuclide concentration. Values of the coefficients of determination $\left(R^{2}\right)$ of the experimental data with the analyzed model were used to compare the simulations of all equations.

To examine the effect of sorbent contact time on $E_{\text {eq }}$, the removal efficiency of both sorbents was measured at different times for the solution containing four studied metal ions. More specifically, samples for radiometric analyses were withdrawn at the time points of $0,0.5,1,2,3,5,10$, $15,30,60,120$ and $180 \mathrm{~min}$. All other parameters were kept identical to those named in Table 1 as the optimum parameters. The results of removal efficiency $\left(E_{\mathrm{R}}\right)$ versus time are given in Fig. 3.

It may be noticed, that the increase of the removal efficiency in the first minutes was very fast and slows down with further increase in the contact time of the phases. Such observations may be related to the change in concentration gradient. It may be reasoned that at the beginning of the process, the large concentration gradient between the sorbent and the liquid phase evokes great sorption rate. For all metals, uptake reaches a plateau within the first $5 \mathrm{~min}$. Specifically, at $t=5 \mathrm{~min}$, the respective $E_{\mathrm{R}}$ values for the CSS-3A sorbent are $98.81 \pm 0.43 \%, 98.84 \pm 0.42 \%, 89.13 \pm 1.01 \%$ and $96.76 \pm 0.36 \%$ for cesium-137, strontium- 85 , europium- 152 and americium-241, respectively. In the case of sorbent CSS-3B, the corresponding values are $98.64 \pm 0.47 \%$, $98.68 \pm 0.42 \%, 90.74 \pm 0.75 \%$, and $96.84 \pm 0.50 \%$. As is seen, the removal efficiency is extremely high for all metals studied. The slight drop observed for Eu(III) versus Am(III) (which is a congener of the former) may be related to its smaller ionic radius [25]: 95 versus $97 \mathrm{pm}$. After the $5 \mathrm{~min}$ time point, it may be observed that the rate of sorption is completely reduced and an equilibrium of the process is reached. This phenomenon may be related to the decreasing availability of the metal unoccupied active sites in the sorbent. The number of the available sites reduces, so the sorption reaches a certain constant value. In addition, elongation of the contacting time does not influence removal efficiency because the concentration gradient remains constant.

Analyzing the obtained results it has been concluded that the pseudo-second-order model fits the best sorption of all metal ions on each of the CSS-3 sorbent. For any metal ion values of the coefficients of determination exceeded 0.95 . 

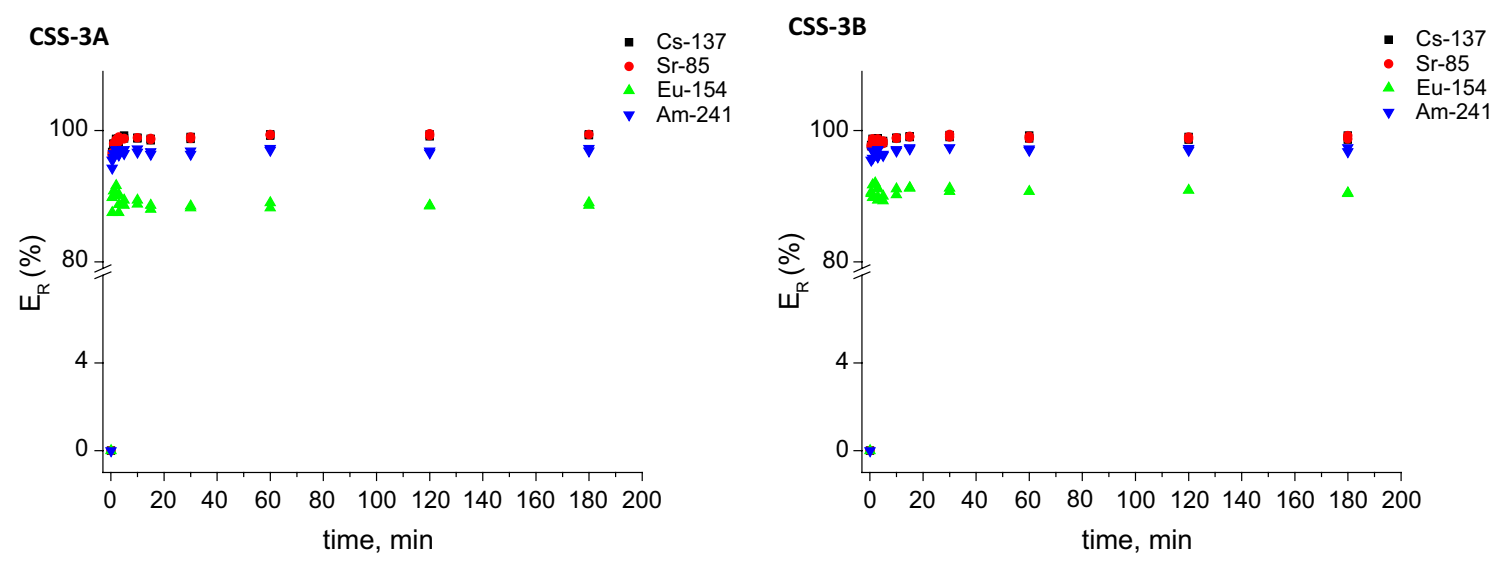

Fig. 3 Effect of contacting time on sorption of the radionuclides onto CSS-3A (left) and CSS-3B (right); linear representation of different models of sorption kinetics for caesium ions

Based on these values, it may be postulated that the ratedetermining step in sorption of any metal ion studied is chemical sorption (chemisorption), which involves valency forces through mutual membership or replacing electrons between sorbent and sorbate [26].

\section{Effect of the sorbent mass on sorption of the radionuclides}

Effect of the sorbent mass on sorption of the radiometal ions is one of the crucial parameters that should be considered for designing the optimum process conditions. All other parameters are presented in Table 1 as the optimum parameters.

Effect of the amount of each sorbent applied for sorption is shown in Fig. 4. As can be seen, the efficiency of decontamination of aqueous solutions from the radioactive metal cations remains constant for the amount of the CSS-3A used is greater than $1 \mathrm{~g} \mathrm{dm}^{-3}$ and up to $20 \mathrm{~g} \mathrm{dm}^{-3}$. For the CSS$3 \mathrm{~B}$ sorbent, up to the amount of $5 \mathrm{~g} \mathrm{dm}^{-3}$, one may observe such growths of the percent of the radionuclide removal $\left(E_{\mathrm{eq}}\right)$. For greater amounts of the CSS3-B, further increase of $E_{\text {eq }}$ is not observed. As a consequence, about $5 \mathrm{~g} \mathrm{dm}^{-3}$ of the CSS-3 material may be proposed optimum for removal of the metal radionuclides independently of their charge. Found in the presented work value is slightly greater than this reported earlier for the CSS-1 materials [19].

It is generally accepted, that growth of the removal percent caused by an increase in adsorbent dose may be attributed to a greater number of the exchangeable sites on the surface of the adsorbent. Plateau observed when the CSS-3 doses were greater than $5 \mathrm{~g} \mathrm{dm}^{-3}$ shows that an equilibrium is reached between the number of ions bound to the adsorbent and the number of free ions in the solution. This equilibrium exists even if the consecutive mass of the sorbent was added, which provided an excess number of the binding sites. In details, for the studied purified solution, which was of the specific activity concentrations of the radionuclides about $8.5 \times 10^{9} \mathrm{~Bq} \mathrm{~g}^{-1}, 8.8 \times 10^{10} \mathrm{~Bq} \mathrm{~g}^{-1}, 1.3 \times 10^{7} \mathrm{~Bq} \mathrm{~g}^{-1}$, and $1.9 \times 10^{6} \mathrm{~Bq} \mathrm{~g}^{-1}$ for $\mathrm{Cs}(\mathrm{I}), \mathrm{Sr}(\mathrm{II}), \mathrm{Eu}(\mathrm{III})$ and $\mathrm{Am}(\mathrm{III})$ (respectively), the corresponding mass concentrations were: $1.9 \times 10^{-8} \mathrm{~mol} \mathrm{dm}^{-3}, 1.2 \times 10^{-8} \mathrm{~mol} \mathrm{dm}^{-3}, 3.4 \times 10^{-9}$ mol dm ${ }^{-3}$, and $1.9 \times 10^{-8} \mathrm{~mol} \mathrm{dm}^{-3}$. As can be seen from Fig. 4, doses of the sorbent being at least $5 \mathrm{~g} \mathrm{dm}^{-3}$ remove completely these amounts of caesium, strontium or americium, while about $80 \%$ of europium.

\section{Effect of the $\mathrm{pH}$ of the purified aqueous solutions}

Review of the existing literature shows, that finding optimum $\mathrm{pH}$ of the solution may result in an increase in the metal removal efficiency $\left(E_{\mathrm{eq}}\right)$. For example, Sparks [27] has stated that sorption of metal cations is $\mathrm{pH}$-dependent and is characterized by a narrow $\mathrm{pH}$ range where sorption increases to nearly $100 \%$, traditionally known as an adsorption edge. The $\mathrm{pH}$ position of the adsorption edge for a particular metal cation is related to its hydrolysis or acid-base characteristics. In addition to $\mathrm{pH}$, sorption of metals is dependent on sorptive concentration, surface coverage, and the type of the sorbent.

Sorption of heavy metals on clay minerals is proposed to be caused by two mechanisms: ion exchange and complexation by the surface binding groups. In the solutions of lower $\mathrm{pH}$, ion exchange process appears to be dominant $[28,29]$. With the increasing $\mathrm{pH}$ of a solution, hydrolysis process becomes more significant and precipitation of metal hydroxides occurs [30, 31].

Results of the removal efficiency $\left(E_{\mathrm{r}}\right)$ of the investigated radioactive metal ions for different $\mathrm{pH}$ of the solution containing these metals in the concentration range of $10^{-6}-10^{-7}$ $\mathrm{M}$ have been obtained for the $\mathrm{pH}$ range from 2 to 12 . It has been found, that $E_{\mathrm{r}}$ values determined for both CSS-3 materials do not change within the whole range of $\mathrm{pH}$ and the results for $\mathrm{Cs}(\mathrm{I})$ are shown in Fig. 5. 

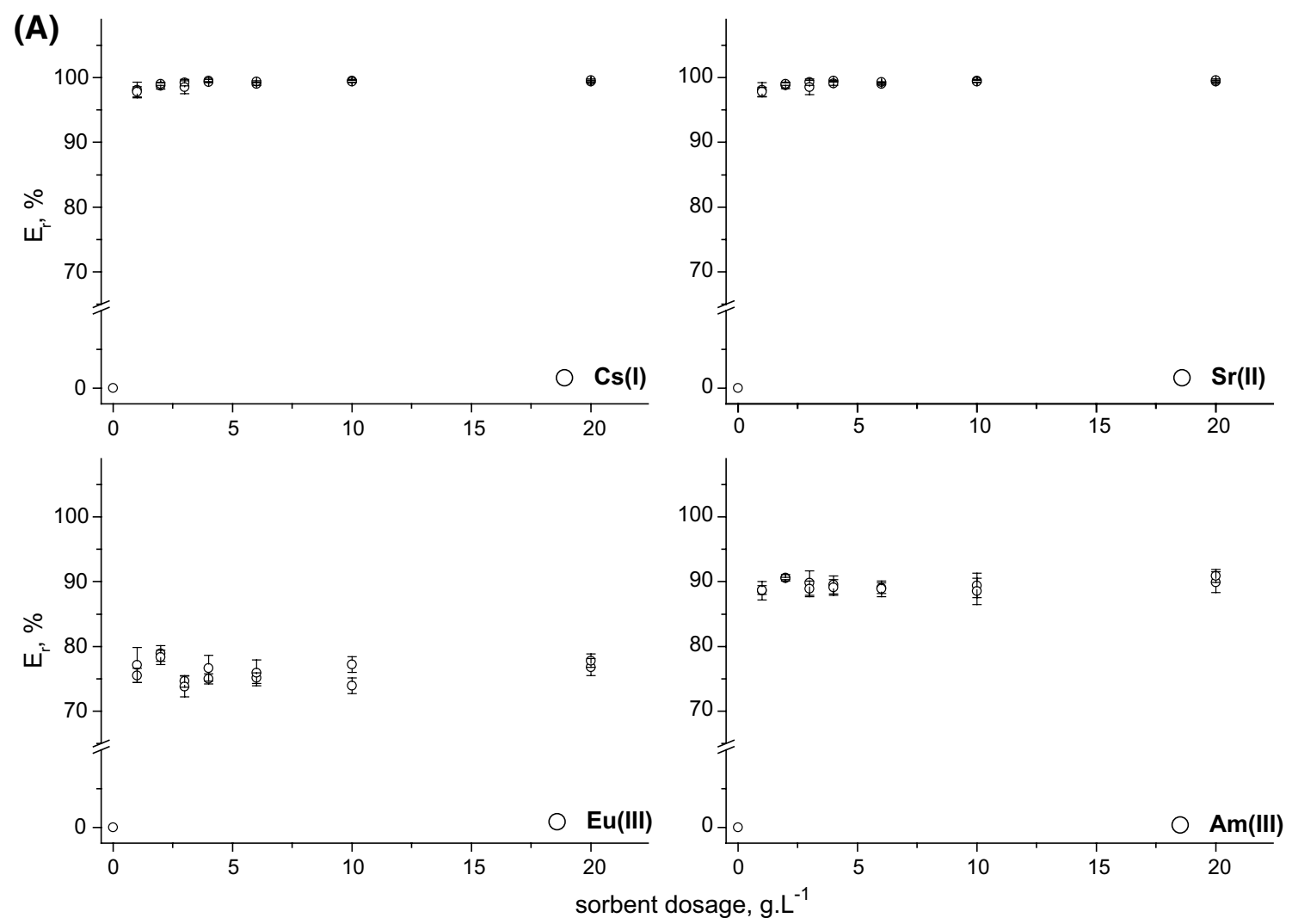

(B)
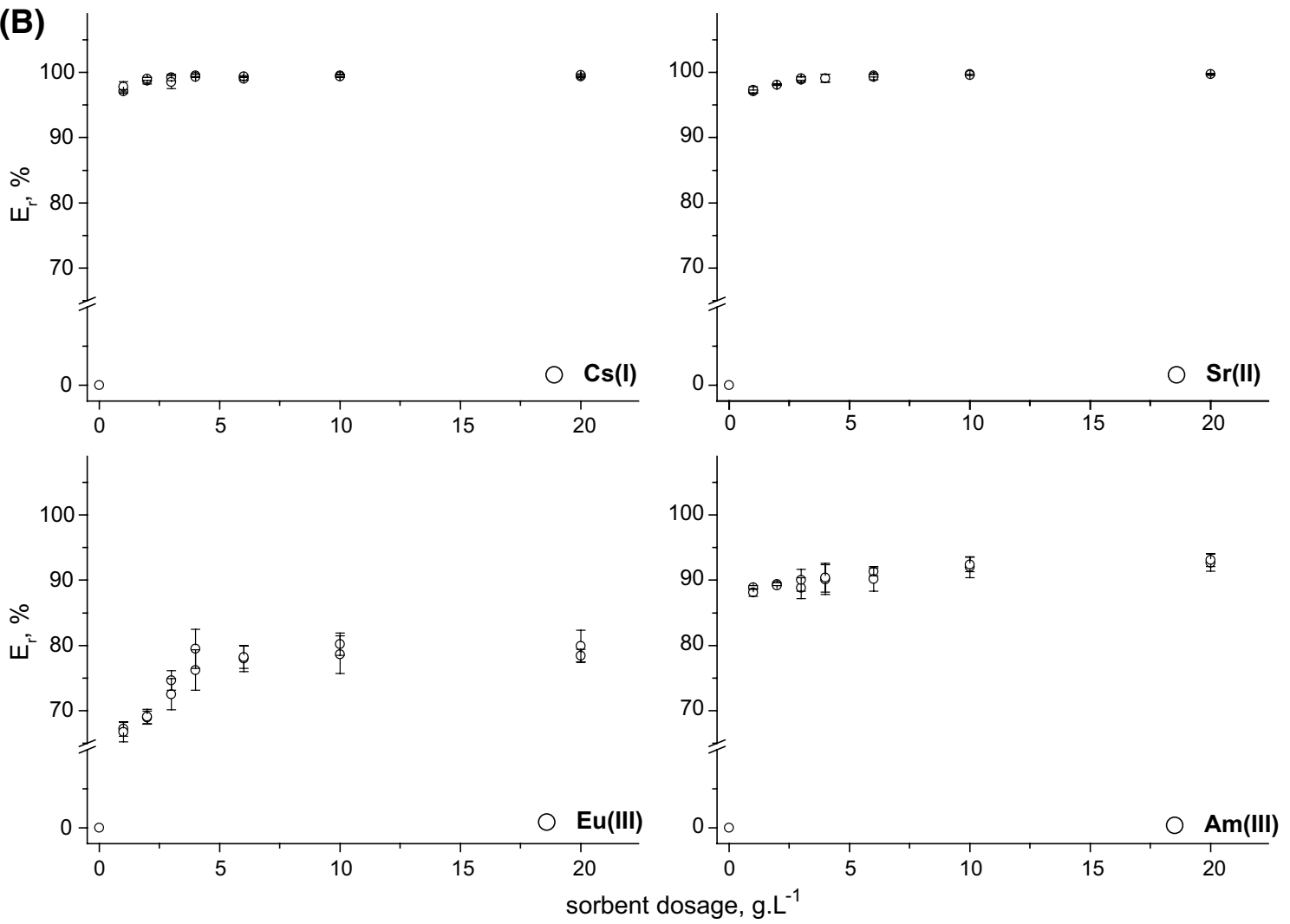

Fig. 4 Removal efficiency $\left(E_{\text {eq }}\right)$ of the radioactive metals plotted against the sorbent dosage; (A) CSS-3A, (B) CSS-3B 
Fig. 5 Removal efficiency $\left(E_{\text {eq }}\right)$ of the radionuclides plotted against the $\mathrm{pH}$

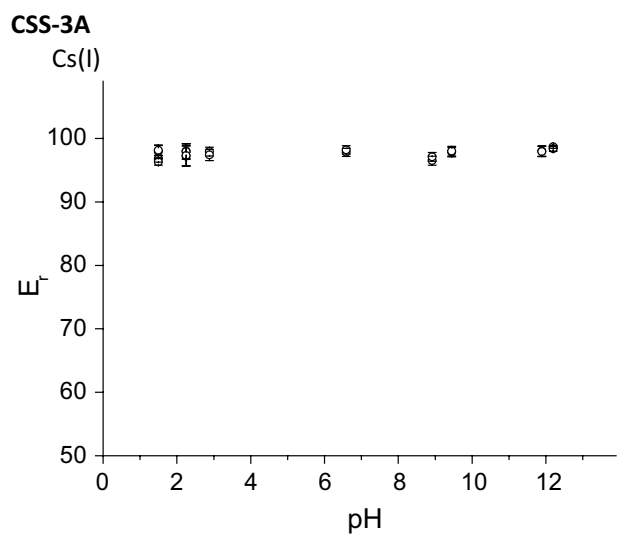

CSS-3B
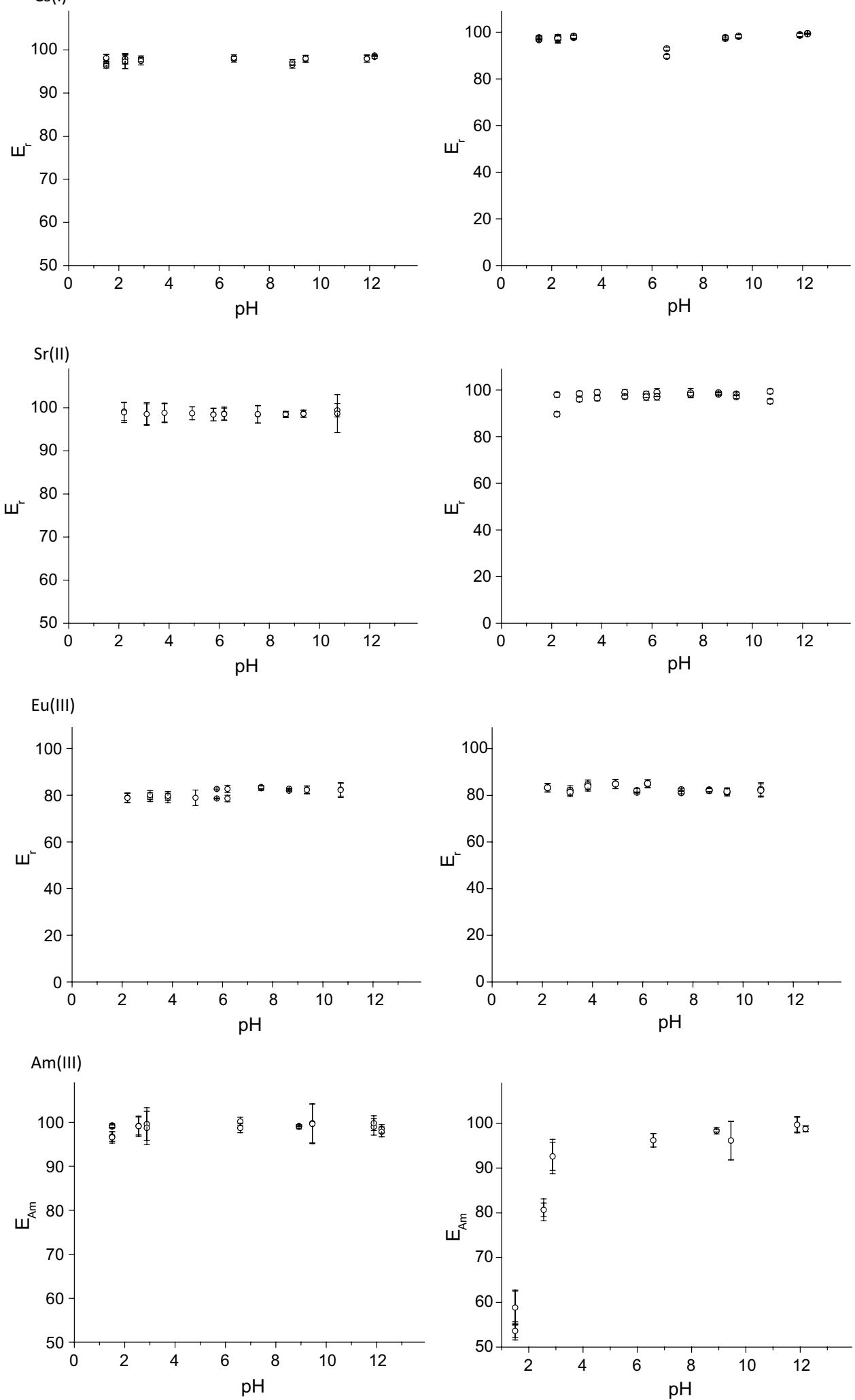
CSS-3A

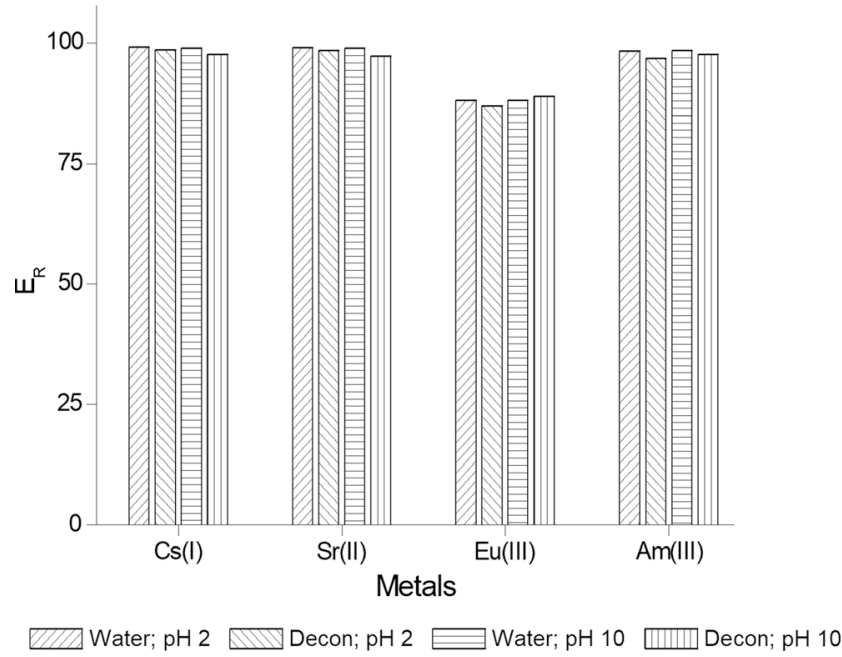

CSS-3B

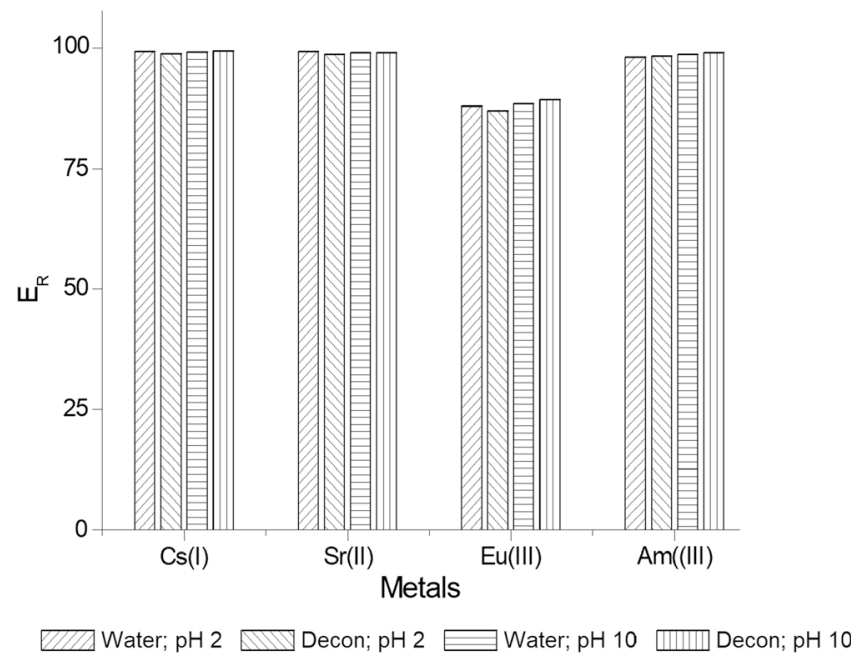

Fig. 6 Comparison of the removal efficiency $\left(E_{\text {eq }}\right)$ of the radionuclides from aqueous solutions and from the solutions containing chelating agents

It has been already shown that sorption of heavy metals on the layered silicates, being primarily an interplay between the adsorption and desorption processes, occurs as a result of the metal interaction with the binding sites of different affinity towards these metals. Binding sites of stronger affinity may be found mainly in a small part of the sorbent surface and their number grows with increasing $\mathrm{pH}$. It was established that they are located on the edge parts of the silicate layers. Those of poorer binding properties, in turn, are ionic sites placed in the interlayer space [32]. Therefore, the observed poor dependence of removal efficiency on the solution acidity may suggest that both CSS-3 materials adsorb the metallic radionuclides primarily due to the radionuclide binding by the ionic sites.

\section{Effect of salts and complexing ligands potentially present in aqueous solutions}

To check whether the CSS-3 sorbents may be applied for the radioactive liquid waste management, we have compared the afore presented experimental results for sorption of the radionuclides from standard laboratory solutions of low salt concentration with the uptake of these metals from the solutions similar to the real liquid radioactive waste. Literature search in the INIS database, which yields with rather a poor dataset, has shown that composition of such wastes differs from each other. So, we have used a solution of the $\mathrm{Na}^{+}, \mathrm{K}^{+}, \mathrm{Mg}^{2+}, \mathrm{Ca}^{2+}$ chlorides in the concentrations resembling these found in aqueous solutions from the Polish the National Radioactive Waste Repository (NRWR). In details, analysis of such sample delivered to our Lab by the NRWR has shown that it contained 583, 32, 129 and $182 \mathrm{mg} \mathrm{dm}^{-3}$ of these cations, respectively. $\mathrm{pH}$ (about 5.5) and the nca radiometal concentration resembles this found for the solution obtained from the NRWR. Results of the removal efficiency $\left(E_{\mathrm{eq}}\right)$ of the radioactive metals by the CSS-3A sorbent from the saline solutions were $98.7 \pm 0.8 \%, 98.7 \pm 0.8 \%$, $94.1 \pm 1.1 \%$ as well as $97.7 \pm 0.8 \%$ for $\mathrm{Cs}(\mathrm{I}), \mathrm{Sr}(\mathrm{II}), \mathrm{Eu}(\mathrm{III})$ and Am(III), respectively. In turn, corresponding $E_{\mathrm{eq}}$ values for the CSS-3B sorbent, are $98.8 \pm 0.8 \%, 98.7 \pm 0.8 \%$, $93.0 \pm 1.5 \%$ and $96.7 \pm 1.3 \%$. Comparison of the data with these mentioned in the previous part of the paper has shown that the presence of the weighted amounts of the salts does not affect the sorption of any of the radioactive metal.

Liquid radioactive wastes may also contain the chelating agents coming from usage of different cleaning solutions. For example, the CANDECON (Canadian Decontamination) lotion: about $2 \times 10^{-3} \mathrm{M}$ of the oxalic and citric acids and Na-EDTA [33]. So, it is to be expected, that certain radioactive wastes may contain all these complexing agents. As a result, to check the prospect sorbents in the processing of the LLRW and/or MLRW, we have studied also sorption of the radionuclides from aqueous solutions containing a mixture of these complexing ligands in the concentrations stated above. The results obtained are presented in Fig. 6 together with the results obtained for aqueous solutions are in the chelating agents. Values of the $\mathrm{pH}$ of the solutions (2 or 10, respectively, which mimic the acidic and basic liquid wastes) were maintained by addition of the appropriate amounts of the hydrochloric acid or sodium hydroxide aqueous solutions.

As it is seen from the Fig. 6, differences in the $E_{\text {eq }}$ values within each pair are small and do not exceed experimental errors. So, it may be concluded that both sorbents may be 

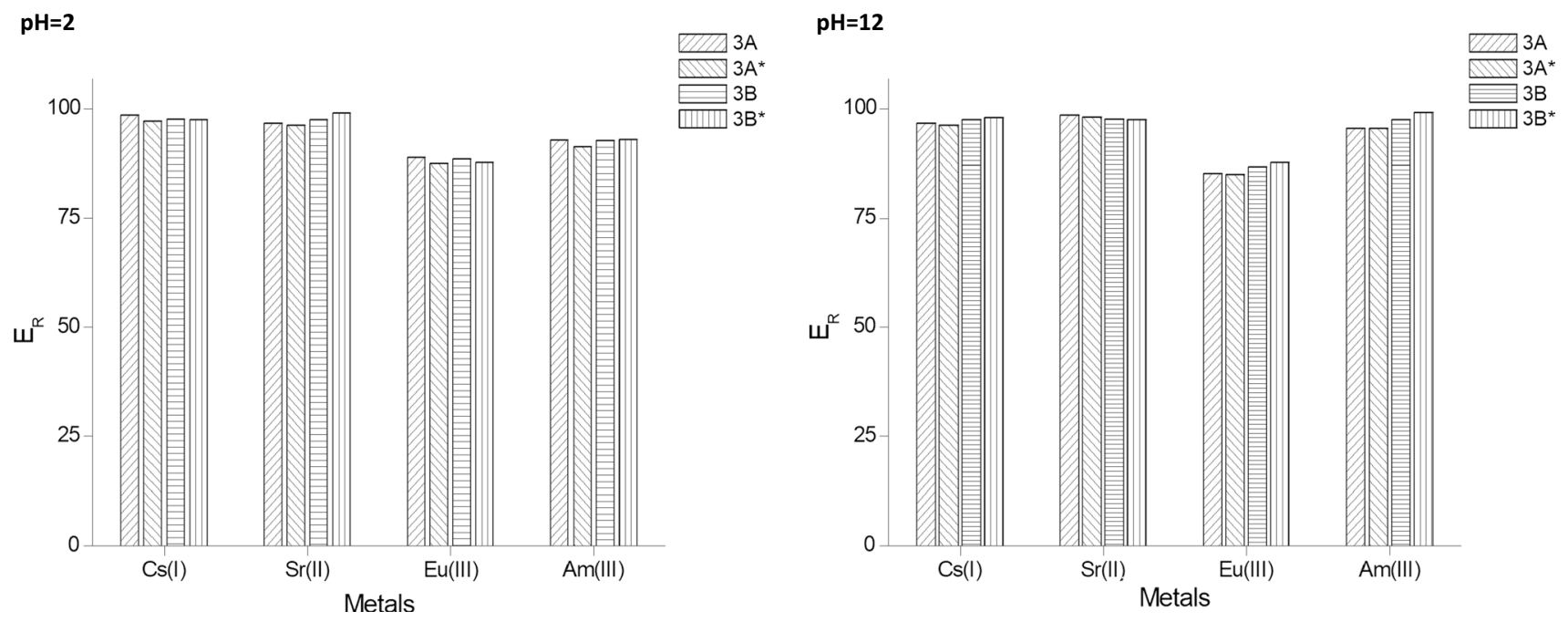

Fig. 7 Radiation stability of the sorbents shown in by sorption of the radionuclides

successively applied for the radioactive liquid wastes containing the chelating agents.

\section{Chemical stability of the sorbents}

Any sorbent which is tested as a potential additive in the engineering barriers designed for the radioactive waste repositories should strongly bind the radioactive metals. So, in present studies, we have carried out the prolonged equilibration $(120 \mathrm{~h})$ of the free from radiometals aqueous liquids with both sorbents prior to the experiment shaken with aqueous solutions containing all the radionuclides. Result obtained has shown that both materials studied may be used to prevent the environment from leaching of the radionuclides. In details, average release of the radionuclides from the CSS-3A sorbent appeared to be $0.14 \pm 0.08 \%, 1.72 \pm 1.10 \%, 1.29 \pm 0.30 \%$ and $0.23 \pm 0.21 \%$ for $\mathrm{Cs}(\mathrm{I}), \mathrm{Sr}(\mathrm{II}), \mathrm{Eu}(\mathrm{III})$ and $\mathrm{Am}(\mathrm{III})$, respectively. Corresponding values for the CSS-3B material were $0.14 \pm 0.07 \%$, $0.37 \pm 0.10 \%, 1.28 \pm 0.52 \%$ and $0.17 \pm 0.54 \%$, one-to-one. Considering the fact, that batch sorption experiments involve extremely intensive agitation, while working conditions in the engineering barriers are close to the equilibrium, obtained results attest potential applicability of both sorbents as a novel additive in the engineering barriers for the radioactive waste repositories.

\section{Radiation stability of the sorbents}

A possible application of any from both materials for the LLRW or MLRW management has been checked by examination their stability under the gamma irradiation. Even, if the main mineralogical components of the CSS-3 materials seem to be radiation stable, some other constituents may be destroyed by their irradiation and change the sorption properties of the materials. For this purpose, both potential sorbents have been irradiated with a dose of $250 \mathrm{kGy}$. Their great radiation stability, i.e. detection of their only insignificant changes after irradiation, has been shown in three independent experiments. Firstly, the sorption properties of both sorbents have been compared for raw materials with these for irradiated. It has been found that the $E_{\mathrm{r}}$ values are comparable within the experimental error for any pair-raw material and the appropriate irradiated sorbent—and any radionuclide (see, Fig. 7).

Furthermore, registered infra-red spectra of the CSS-3 sorbents have been numerically compared for the non-irradiated materials with these for the irradiated. Assignment of main peaks found in the so-called fingerprint region (namely, $2000-400 \mathrm{~cm}^{-1}$ ) for the clays may be found in the available, e.g. in the papers of Bhaskar [34] or Bendou [35]. Because, for the comparative rather than analytical purpose it is not crucial, only in short: the bands seen nearby $460 \mathrm{~cm}^{-1}$ may be related to the $\mathrm{Si}-\mathrm{O}-\mathrm{Al}$ and $\mathrm{Si}-\mathrm{O}-\mathrm{Si}$ bending vibrations. Strong bands in the area of about $1000-1050 \mathrm{~cm}^{-1}$ may be related to the $\mathrm{Si}-\mathrm{O}$ stretching vibrations (in-plane) of the tetrahedral sheets. Peaks in the region of $3600 \mathrm{~cm}^{-1}$ may be linked with the stretching vibrations of hydroxyl groups which are bound to the octahedral $\mathrm{Al}^{3+}$ cations. Finally, bands at around $1450 \mathrm{~cm}^{-1}$ and $3400-3500 \mathrm{~cm}^{-1}$ (the latter, lying outside the fingerprint region) should be assigned to the bending and stretching vibrations of the hydroxyl groups of water molecules settled on the surface of the clay [34, 35]. It is worth to notice, that peak at $1450 \mathrm{~cm}^{-1}$, present in spectra of the CSS-3A sorbent, is missing in the spectra of the CSS-3B.

As in our previous paper [19], computation of the Pearson's correlation coefficient (p.c.c) has been chosen as the 
Fig. 8 IR spectra registered for both CSS-3 materials. For the raw materials are shown in the upper part, while for the gamma-ray irradiated in below. Left column presents spectra of the $3 \mathrm{~A}$ potential sorbent and right—of the $3 \mathrm{~B}$ material

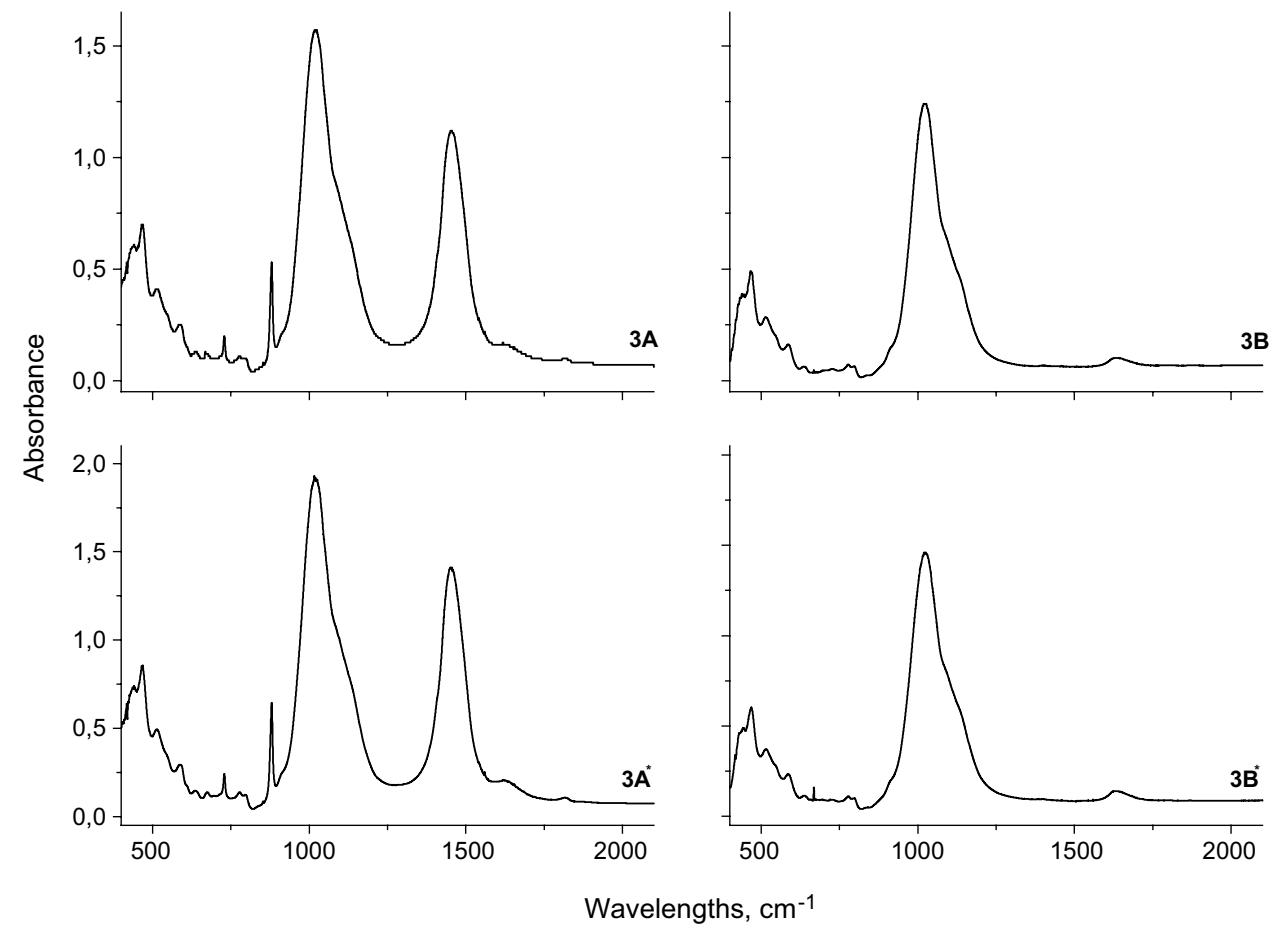

best way for comparing two spectra. Values of the p.c.c. should be in the range between -1 to 1 . A value close to zero means that poor correlation exists for the analyzed spectra, i.e. the spectra differ each other. In turn, values nearby \pm 1 describe a pair of spectra being to a large extent similar and therefore which characterize substances to a large extent analogous.

Within the framework of presented studies, it has been found that the p.c.c. values for spectra registered for both pairs of materials (i.e. for the original clays and the corresponding materials after their gamma irradiation) are 0.98 and 0.91 , respectively. All analyzed spectra are shown in Fig. 8. These values, close to 1 , suggest that raw materials do not change significantly upon their irradiation and are sufficiently radiation stable to be applied for the LLRW management.

Finally, it is the known fact, that any material gains spontaneously some electrical charge on the surface upon interaction with surrounding polar solvents (e.g. water). The charge is mostly negative. This phenomenon is called Zeta Potential (ZP) and may originate from: (1) different affinity towards electrons of both phases; (2) ionization of binding groups located on surface of the solid; (3) adsorption of numerous ions from the electrolyte on the solid surface; (4) dissolution of certain ions present in the crystal lattice (5); anisotropy of the surface, or/and (6) isomorphous substitution. Therefore, $Z P$ of the material is often assumed as a meaningful factor for characterization of the material. So, to examine if the CSS-3 materials change upon the action of gamma radiation, values of $\mathrm{ZP}$ have been determined for both pairs: raw materials and after their irradiation. Obtained data are presented in Table 2 .

Inspection of the obtained data has shown that for each acidity of water, values of the $Z P$ are negative and equal for both sorbents. They do not change in course of their irradiation. Such negative values show that both materials may be applied as sorbents for metal ions present in the aqueous waste solutions.

Summarizing, great radiation stability of both sorbents proven by three independent methods supports our expectation that they may be successfully applied for the radioactive waste management.

\section{Removal of technetium-99 from aqueous solutions}

Technetium does not occur naturally and all three known isotopes of technetium (Tc-97, Tc-98, and Tc-99) are radioactive. The most important one, technetium-99 (Tc99) is produced during nuclear reactor operation, and as

Table 2 Zeta potentials of CSS-3 materials, for the raw samples of the sorbents (3A and 3B) and after gamma-ray irradiation; measurements in solutions of different acidity

\begin{tabular}{lllll}
\hline $\mathrm{pH}$ & \multicolumn{4}{l}{ Zeta potential $[\mathrm{mV}]$} \\
\cline { 2 - 5 } & 3A & 3A (irradiated) & 3B & 3B (irradiated) \\
\hline 4 & -25.5 & -25.6 & -24.4 & -24.2 \\
7 & -18.5 & -18.5 & -18.2 & -18.9 \\
11 & -35.5 & -35.9 & -37.1 & -38.5 \\
\hline
\end{tabular}


CSS-3A

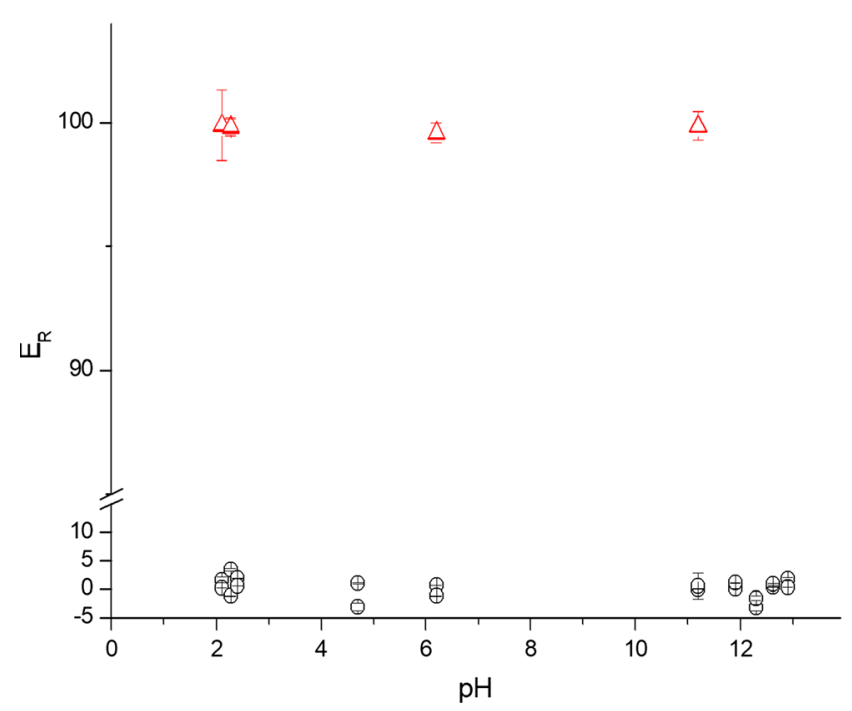

CSS-3B

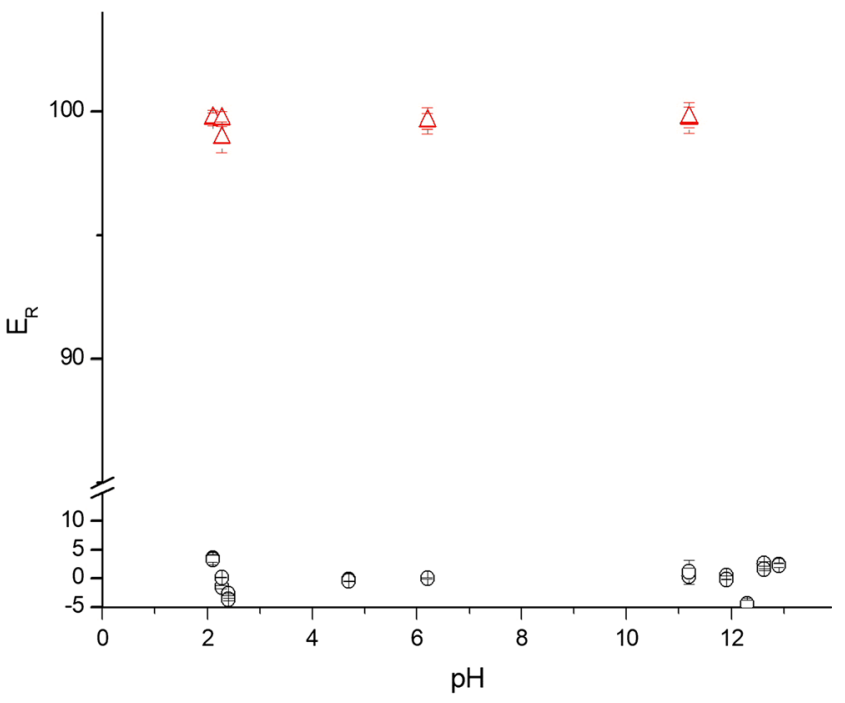

Fig. 9 Sorption of pertechnetate-Tc-99m by the CSS-3 sorbents $(O)$ and after addition of $\mathrm{SnCl}_{2}$ as the reducing agent $(\Delta)$

a by-product of nuclear weapons explosions. So, it can be found also in the high radioactivity level nuclear wastes containing spent nuclear fuel. A lesser amount of Tc-99 can also be present in waste generated at medical laboratories and academic institutions. As Tc-99 radionuclide is an object rarely investigated in the sorption studies, we decided to extend the presented work with its sorption by both CSS materials. To facilitate the radiometric measurements, we profiled the gamma-ray-emitting, metastable, Tc-99m radionuclide, at present widely used for medical diagnostic examinations.

Technetium occurs either in the form of the tetrahedral pertechnetate anion, $\mathrm{TcO}_{4}{ }^{-}$or as a simple $\mathrm{Tc}^{4+}$ cation. Pertechnetate behaves analogously to perchlorate and unlike permanganate $\left(\mathrm{MnO}_{4}{ }^{-}\right)$is only a weak oxidizing agent. It is highly mobile and long-lived radioactive species, so protecting the humans and development of the best remediation strategies is urgently needed. Because of the anionic structure of the dominant technetium form in the environment, it is expected to be poorly sorbed by each of the CSS-3 sorbents. However in reaction with strong reducing agents, primarily stannous ions but also hydrazine, borohydride, ascorbic acid or zinc results with complete reduction of the pertechnetates. So, in the present work, we checked the possibility of the technetium sorption on the CSS-3 sorbents, both pertechnetate and with the addition of the reducing agents which should enhance sorption of the radioactive element. In spite of the fact that $\mathrm{Fe}(\mathrm{II})$ reducing agent is usually found in the liquid wastes, this reduction is known as not reduce the pertechnetate ions. So, in the presented work, we have chosen $\mathrm{SnCl}_{2}$ and ascorbic acid which is commonly used as a component of the kits used for preparing the technetium radiopharmaceuticals [38]. Obtained results are summarized in Fig. 9.

Sorption of the pertechnetate anion by each of the sorbent is poor: the $E_{\mathrm{Tc}}$ value is close to zero. Addition of the stannous chloride results in the significant increase of the technetium sorption ( $\mathrm{E}_{\mathrm{Tc}}$ approaches $100 \%$ ).

Use of the ascorbic acid as a reducing agent alternative to the stannous chloride has been also tested. It has been found that $E_{\text {eq;Tc }}$ also exceeds $99 \%$ both in the acidic and basic solutions.

\section{Conclusions}

Adsorption process may be considered among the most efficient methods of removing the metal ions from aqueous media. Generally, the efficiency of adsorption is comparable to another chemical or physical procedures of decontamination, however, it is much cheaper [36]. A great number of low-cost adsorbents have been already tested, among them clays, zeolites, hydrous oxides of different metals. Because review of the International Atomic Energy Agency (IAEA) literature database INIS provides about 20,000 records related to the radioactive metal sorption from aqueous solutions, selection of the data on sorption of strontium(II) and americium(III) has been published in one of our previous papers [37]. Comparison of the data presented here with sorption properties of the CSS sorbents shows that the latter is of the same range as the representatives of another group of the natural sorbents.

Clay-salt slimes (CSS), waste produced by the "Belaruskali" factory, are proposed as cheap, eco-friendly 
Table 3 Main results obtained for the CSS-1 and CSS-3 sorbents

CSS-1A [19]

CSS-1B [19]

CSS-3A

CSS-3B

(Present paper)

\begin{tabular}{|c|c|c|c|c|}
\hline Proposed equilibration time (min) & $10 \mathrm{~min}$ & $10 \mathrm{~min}$ & $10 \mathrm{~min}$ & $10 \mathrm{~min}$ \\
\hline Proposed sorbent dosage $\left(\mathrm{g} \mathrm{dm}^{3}\right)$ & 2 & 2 & 2 & 5 \\
\hline Optimum pH & \multicolumn{2}{|c|}{$\begin{array}{l}\text { Does not change significantly within the } \mathrm{pH} \text { range } \\
2-12\end{array}$} & \multicolumn{2}{|c|}{$\begin{array}{l}\text { Does not change significantly within the } \mathrm{pH} \\
\text { range } 2-12\end{array}$} \\
\hline Zeta potential $(\mathrm{pH}=4) ; \mathrm{mV}$ & -20.1 & -22.5 & -25.5 & -24.4 \\
\hline \multicolumn{5}{|l|}{ Main components [20]: } \\
\hline Illite & $44.2 \%$ & $61.2 \%$ & $48.2 \%$ & $65.2 \%$ \\
\hline Dolomite & $23.0 \%$ & 0 & $17.0 \%$ & 0 \\
\hline Radiation stability & very high & very high & very high & very high \\
\hline \multicolumn{5}{|c|}{$E_{\mathrm{R}}(\%)$ of the initial radionuclide content in the solution ${ }^{*}$} \\
\hline $\operatorname{Cs}(\mathrm{I})$ & $99.0 \pm 0.3$ & $98.6 \pm 0.2$ & $98.8 \pm 0.4$ & $98.6 \pm 0.5$ \\
\hline $\mathrm{Sr}(\mathrm{II})$ & $99.0 \pm 0.4$ & $98.4 \pm 0.3$ & $98.8 \pm 0.4$ & $98.7 \pm 0.4$ \\
\hline $\mathrm{Eu}(\mathrm{III})$ & $91.1 \pm 0.6$ & $87.0 \pm 0.5$ & $89.1 \pm 1.0$ & $90.7 \pm 0.7$ \\
\hline Am(III) & $97.4 \pm 0.2$ & $92.3 \pm 0.2$ & $96.8 \pm 0.4$ & $96.8 \pm 0.5$ \\
\hline $\mathrm{Tc}(\mathrm{IV}) / \mathrm{SnCl}_{2}$ & - & - & $99.6 \pm 0.3$ & $99.5 \pm 0.4$ \\
\hline
\end{tabular}

*For the conditions listed in Table 1 as optimum

materials for application as sorbents efficient in removal of the radionuclides from aqueous solutions. In the presented work, sorption of caesium(I), strontium(II), europium(III), americium(III) and technetium(VII) has been studied.

Main results obtained for two fractions of the CSS-3 sorbent which were obtained from material collected in the Mining Factory No 3 of the "Belaruskali" are presented in Table 3 and compared with the sorbent got from the wastes obtained from the Mining Factory No 1. The latter sorbent has been earlier described in [19].

Results of the presented work on the clay-salt slimes, that are industrial wastes in the activity of the "Belaruskali", show that these materials may be accounted as a perspective sorbent for treatment of aqueous solutions containing the radioactive metals.

Acknowledgements Part of this research was made in parts sponsored by the Innovation Centre "Skolkovo" (Moscow, Russia) by mini-grant MG 72/16 issued for Leanid MASKALCHUK. We are grateful to Mrs. Wanda DALECKA (INCT, Warsaw) for effective assistance in the experimental work and acknowledge Dr. Wojciech GLUSZEWSKI (also from the INCT, Warsaw) for gamma irradiation of the samples.

\section{Compliance with ethical standards}

Conflict of interest The authors state that there is no conflict of interest in presented work.

Open Access This article is distributed under the terms of the Creative Commons Attribution 4.0 International License (http://creativeco mmons.org/licenses/by/4.0/), which permits unrestricted use, distribution, and reproduction in any medium, provided you give appropriate credit to the original author(s) and the source, provide a link to the Creative Commons license, and indicate if changes were made.

\section{References}

1. http://www.paa.gov.pl/uploads/temp/strony/strona_401/text_ images/PAA_Annual_Report_2016_readable_1.pdf. Accessed 12 Feb 2019

2. Cholerzynski A (2018) Management of the radioactive waste and spent nuclear fuel in Poland. Lecture on the Seminar "Management of the radioactive waste and spent nuclear fuel in Poland". http://seren.org.pl/wp-content/uploads/2018/10/Postepowanie-Zodpadami-promiebiotworczymi_10.2018.pdf. Accessed Oct 2018. (in Polish)

3. http://www.oecd-nea.org/ndd/pubs/2010/6350-waste-perspectiv e.pdf. Accessed 12 Feb 2019

4. Krishnamoorthy TM, Joshi SN, Doshi GR, Nair RN (1993) Desorption kinetics of radionuclides fixed in cement matrix. J Nucl Chem Technol. 104:351-357

5. Barre B, Le Dars A, Acker A, Barre B, Bucaille A, Ellia G, Garderet P, Greneche D, Jamard M, Kaluzny Y, Watteau M (2008) All about nuclear energy, from atom to zirconium. AREVA Communications Department, Paris, pp 100-101

6. El-Kamash AM, El-Dakroury AM, Aly HF (2002) Leaching kinetics of ${ }^{137} \mathrm{Cs}$ and ${ }^{60} \mathrm{Co}$ radionuclides fixed in cement and cementbased materials. J Cem Concr Res 32:1797-1803

7. El-Kamash AM, El-Naggar MR, El-Dessouky MI (2006) Immobilization of cesium and strontium radionuclides in zeolite-cement blends. J Hazard Mater B136:310-316

8. IAEA (2001) Performance of engineered barrier materials in near surface disposal facilities for radioactive waste, IAEA-TECDOC-1255, Vienna

9. IAEA (2013) Characterization of swelling clays as components of the engineered barrier system for geological repositories, IAEATECDOC-1718, Vienna 
10. Abdel Rahman RO, Zin El Abidin DHA, Abou-Shady H (2013) Assessment of strontium immobilization in cement-bentonite matrices. Chem Eng Journal. 228:772-780

11. Sčiglo $T$ (2015) Titanium silicates of the formula $\left(\mathrm{Na}_{2} \mathrm{Ti}_{2} \mathrm{SiO}_{7} \cdot 2 \mathrm{HO}\right)$ as sorbent for the actinides; Sorption of cesium, americium and plutonium radionuclides on synthetic and natural sorbents, Summary of doctoral dissertation, Vilnius, University, Vilnius. https://epublications.vu.lt/object/elaba:15427 413/15427413.pdf. Accessed 12 Feb 2019

12. Lujaniene G, Motiejunas S, Šapolaito J (2007) Sorption of Cs, Pu and Am on clay minerals. J Radioanal Nucl Chem 274:345-353

13. Galambos M, Paucova V, Kufcakova J, Rosskopfova O, Rajec P, Adamcova R (2010) Cesium sorption on bentonites and montmorillonite K10. J Radioanal Nucl Chem 284:55-64

14. Andrade E, Madruga MJ, Bobos I, Paiva MI, Maia F, Mateus A, Trindade R, Freitas MC, Goncalves MA (2010) Characterization of portuguese geomaterials, the clay component of Rañas, as potential liners for low and intermediate radioactive disposal sites. J Radioanal Nucl Chem 286:777-783

15. Galambos M, Rosskopfova O, Kufcakova J, Rajec P (2011) Utilization of slovak bentonites in deposition of high-level radioactive waste and spent nuclear fuel. J Radioanal Nucl Chem 288:765-777

16. Adamcova R, Suraba V, Krajnak A, Rosskopfova O, Galambos M (2014) First shrinkage parameters of Slovak bentonites considered for engineered barriers in the deep geological repository of highlevel radioactive waste and spent nuclear fuel. J Radioanal Nucl Chem 302:737-743

17. Maskalchuk L, Baklay A, Leontieva T (2016) Chemical and mineralogical aspects of clay-salt slimes of "Belaruskali" using for the preparation of nanostructured sorbents of radionuclides. Procedia Chemistry. 21:394-400

18. Leont'eva T, Baklay A, Maskal'chuk L (2016) Perspective of clay-salt slimes of JSC "Belaruskali" use for clearing of aquatic medium and ecosystems from radiocaesium. In: Proceedings of the BSTU. Series III. Chemistry and Technology if Inorganic Substances, vol 3, pp 74-80. (in Russian)

19. Fuks L, Herdzik-Koniecko I, Maskalchuk L, Leontieva T (2018) Application of industrial wastes as an engineering barrier in radioactive waste repositories: sorption of $\mathrm{Cs}(\mathrm{I}), \mathrm{Sr}(\mathrm{II}), \mathrm{Eu}(\mathrm{III})$, and Am(III) ions on the clay-salt slimes of the joint stock company "Belaruskali". Int J Environm Sci Technol 15:2047-2058

20. Maskalchuk L, Fuks L, Baklay A, Leontieva T, Herdzik-Koniecko I (2018) Nanostructured aluminosilicate sorbents of radionuclides based on the clay-salt slimes of JSC "Belaruskali": physicochemical properties and application. Russ Radiochemistry (in the process)

21. Heuel-Fabianek B (2014) Partition coefficients $\left(K_{d}\right)$ for the modelling of transport processes of radionuclides in groundwater. JÜLBerichte, Forschungszentrum Jülich. 4375:11

22. de Goeij JJ, Bonardi ML (2005) How do we define the concepts specific activity, radioactive concentration, carrier, carrier-free and no-carrier-added? J Radioanal Nucl Chem 263:13-18
23. Shannon RD (1976) Revised effective ionic radii and systematic studies of interatomic distances in halides and chalcogenides. Acta Crystallographica Section A 32:751-767

24. Staron P, Chwastowski J, Banach M (2017) Sorption and desorption studies on silver ions from aqueous solution by coconut fiber. J Clean Prod 149:290-301

25. Siekerski S, Burgess J (2002) Concise chemistry of the elements. Ellis Horwood series in chemical science. Woodhead Publishing, Sawston (eBook ISBN-9781782420453). ISBN-9781898563716

26. Ho YS, McKay G (1999) Pseudo-second order model for sorption processes. Process Biochem 34:451-465

27. Sparks Donald L (ed) (2003) Sorption phenomena on soils, environmental soil chemistry, 2nd edn. Academic Press, London, pp $133-186$

28. Holm TR, Zhu X (1994) Sorption by kaolinite of $\mathrm{Cd}^{2+}, \mathrm{Pb}^{2+}$ and $\mathrm{Cu}^{2+}$ from landfill leachate-contaminated groundwater. J Contam Hydrol 16:271-287

29. Stadler M, Schindler PW (1993) Modeling of $\mathrm{H}^{+}$and $\mathrm{Cu}^{2+}$ adsorption on calcium-montmorillonite. Clays Clay Miner 41:288-296

30. Smith E, Lu W, Vengris T, Binkiene R (1996) Sorption of heavy metals by Lithuanian glauconite. Water Res 30:2883-2892

31. Appel C, Ma L (2002) Concentration, pH, and surface charge effects on cadmium and lead sorption in three tropical soils. J Environ Qual 31:581-589

32. Undabeytia T, Nir S, Rytwo C, Serban C, Morillo E, Maqueda C (2002) Modeling adsorption-desorption processes of $\mathrm{Cu}$ on edge and planar sites of montmorillonit. Environ Sci Technol 36:2677-2683

33. Dulama M, Deneanu N, Pavelescu M, Pasăre L (2009) Combined radioactive liquid waste treatment processes involving inorganic sorbents and micro/ultrafiltration. Rom J Phys 54:851-859

34. Bhaskar JS, Satya RG, Roshmi B, Indu BR, Rashmi R (2015) Spectroscopic characterization and quantitative estimation of natural weathering of silicates in sediments of Dikrong River, India. J Modern Phys 6:1631-1641

35. Bendou S, Amrani M (2014) Effect of hydrochloric acid on the structural of sodic-bentonite clay. J Min Mater Character Eng 2:404-413

36. Fu F, Wang Q (2011) Removal of heavy metal ions from wastewater; a review. J Environ Manag 92:407-418

37. Fuks L, Oszczak A, Dudek J, Majdan M, Trytek M (2016) Removal of the radionuclides from aqueous solutions by biosorption on the roots of the dandelion (Taraxacum officinale). Int $\mathrm{J}$ Environ Sci Technol 13:2339-2352

38. Saha GB (1979) Fundamentals of nuclear pharmacy. SpringerVerlag, New York, p 88

Publisher's Note Springer Nature remains neutral with regard to jurisdictional claims in published maps and institutional affiliations. 